\title{
Marco Bevolo: The golden crossroads- multidisciplinary findings for business success from the worlds of fine arts, design and culture
}

\author{
Palgrave Macmillan, Houndsmills, 2010, ISBN 978-0-230-22418-6
}

\author{
Wilfred Dolfsma
}

Published online: 21 March 2010

(C) The Author(s) 2010. This article is published with open access at Springerlink.com

Seldom does one find a book that makes such far-reaching claims as The Golden Crossroads. Bevolo believes that a study of the fine arts and of design will teach everybody such fundamental things that people will start thinking and acting in fundamentally different ways. The "deep crisis of our financial systems ... [which] is not just an economic crisis: it is an ideological crisis, and a spiritual one" (p. 1) will disappear once it is realized, after reading this book, that the "way of doing business" and the "MBA culture" need to be redirected. These and other statements are grand claims one expects to hear from preachers or gurus in the business community. In line with this, the book's main strength lies in the repetitive nature of its composition. There is also quite a bit of reference to authority and authorities. Bevolo indicates that he knows that the statements are bold.

Ironically, perhaps, there is much in the structure of the book that reminds one of the work of gurus in the business community or textbooks for sophomore students who might consider going to business schools. Each chapter starts with key findings which are then returned to at the end of the chapter. Chapters are thus structured as elaborations of lists presented early on.

It is clear that a reader who is even slightly positivistic will be turned off quite soon, if not by the style, then by the apparent lack of structure and purpose. The book does not obviously work toward something. After a brief introduction, an 11-point manifesto is presented which aims to help people "redesign the way we do business, regenerate the way we do marketing, and rethink the essence and the meanings of what we do" (p. 7). The points from the manifesto are then loosely returned to in nine chapters in four parts. Each chapter contains "findings" that number to a total of 38 in those nine chapters. The points from the manifesto are quite opaque at times (" 3 . Culture is everywhere, from the cathedral to the favelas: immerse yourself in culture at all levels, by all means"; p. 6), quite naïve at other

W. Dolfsma (西)

School of Economics and Business, University of Groningen, Groningen, The Netherlands

e-mail: w.a.dolfsma@ rug.nl 
times ("8. ... there are no tactics, take every decision as if its impacts was eternal."; p. 6). The findings are of an equally mixed nature: "understand the actionable power of creativity", "discover the most engaged customer in the world". Points from the manifesto seem quite unrelated to the findings.

When presenting findings and discussing them in the chapters, Bevolo draws, in a rather ad hoc manner, on examples from the field of fine arts and design that he obviously knows well. He draws especially from examples in Italy and the Netherlands, countries where he has spent much of his time both as a private individual and as a professional. Academics, or skeptics, would in many of these cases like to know how representative the examples are. Is the broad claim supported? Why is an example relevant? Few readers are likely to know about all of the examples presented and may take the stories at face value even though an uneasy feeling may linger. The uneasy feeling may start to be a nagging feeling when an example presented clearly does not support a claim so boldly stated. The Nederlands Fotomuseum (Rotterdam) may, for instance, be the least obvious example of an organization in the cultural domain that has "managed to build [a relationship] within its physical and local environment" (p. 132) and for "bringing [its] very soul into society and improving the social conditions" (p. 133). There has been a protracted and fundamental debate about where this institute, primarily publically funded, was to be located: Rotterdam or Amsterdam. This case study is thus not a good choice to illustrate local relationships or much of a role-model of how to be a sustainable business.

Much of what is offered as new and groundbreaking is already well-established in the area of business studies. The need to connect with the most engaged customers is one example, referred to as "lead users" in business studies literature (Von Hippel 2005). Established criticisms of such ideas are also not discussed by Bevolo, like the idea that lead users can be leading a firm away from a large market where ultimately profit is to be made.

Most of the chapters could benefit from more substance, more use of what is available in the literature, and more analysis of empirical material in addition to the insights of consulted experts that Bevolo provides. To this reviewer's surprise, a quantitative method is mentioned in Chap. 9 that deals with the future of the fine arts. One would expect such a theme to be one that the delphi method of consulting experts would be best fitted for. Rather, Bevolo employs what he calls a "sophisticated quantitative market research method" that involves using "proprietary algorithms" developed by Vice-Presidents and Chief Technology Officers of some firm based in the USA on a "statistically chosen sample of ordinary people" in the UK and the USA. The method itself is not well explained by Bevolo, leaving one in some doubt as to whether it was correctly applied. What follows is information on the number of people in the total sample, and subsamples within that, who agreed with certain statements. Thus, the truth of the statements was "tested" in a "statistically sound" manner. It is unclear how the full population was defined, how the sample selection was made, what response rate emerged, and what bias might be included in the data.

It is very clear that this reviewer is not too impressed with this book. Many a reader is likely to be disappointed after opening it. Zealots, however, will probably 
be convinced from page 1 of the fundamental nature and deep truth of what Bevolo has to offer. Business men and women, a main target audience for the book, may learn something nonetheless as they are temporarily jostled away from their usual way thinking. For such a jostle to have a lasting effect, much more substance is needed than Bevolo offers in The Golden Crossroads.

Open Access This article is distributed under the terms of the Creative Commons Attribution Noncommercial License which permits any noncommercial use, distribution, and reproduction in any medium, provided the original author(s) and source are credited.

\section{Reference}

Von Hippel, E. (2005). Democratizing innovation. Cambridge, MA: MIT Press. 